\title{
Single nucleotide polymorphisms between two lines of European bison (Bison bonasus) detected by the use of Illumina Bovine $50 \mathrm{~K}$ BeadChip
}

\author{
S. Kaminski $\cdot$ W. Olech $\cdot$ K. Olenski $\cdot$ \\ Z. Nowak $\cdot$ A. Rusc
}

Received: 25 June 2011 / Accepted: 22 September 2011/Published online: 4 October 2011

(C) The Author(s) 2011. This article is published with open access at Springerlink.com

\begin{abstract}
The population of European bison is divided into two lines: the Lowland-Bialowieza (LB) and the LowlandCaucasian (LC). Because of a very high level of inbreeding and the bottleneck effect, the use of routine sets of cattle microsatellite markers does not reveal significant differences between these genetic lines. Within the research we attempted to overcome this limitation by the use of a Single Nucleotide Polymorphisms panel (50 K Bovine BeadChip, Illumina). Genomic DNA was isolated from the blood of 10 European bison (5 LB and $5 \mathrm{LC}$ ) of known pedigrees. The total call rate of genotypes was equal to $93.5 \%$. From a total of 54,001 SNPs-only 1,337 were shown to be polymorphic. Significant differences $(P<0.05)$ between the two lines in allele frequencies were found in 50 markers. Fourteen of them were shown monomorphic in one of the line and polymorphic in the another. The results confirm very low genetic variability of European bison and provide a new tool for finding genetic differences between the two lines.
\end{abstract}

Keywords European bison - Genetic diversity - SNP . Conservation management

European bison could originally be found throughout the continent and consisted of two populations: in the Białowieza Forest in Poland (Bison b. bonasus) and in the northwest Caucasus (Bison b. caucasicus). The last free roaming

S. Kaminski $(\bowtie) \cdot$ K. Olenski · A. Rusc

Department of Animal Genetics, University of Warmia and Mazury, 10-718 Olsztyn, Poland

e-mail: stanislaw.kaminski@uwm.edu.pl; stachel@uwm.edu.pl

W. Olech $\cdot$ Z. Nowak

Department of Animal Genetics and Breeding, Warsaw

University of Life Sciences, 02-786 Warsaw, Poland
European bison was shot in Poland in 1919, and the last individual in the Caucasus region died before 1927 (Heptner et al. 1966; Pucek et al. 2004). After their extinction in the wild, European bison were restored from a few individuals preserved in zoological gardens. The current population of EB is highly inbred as a result of the bottleneck effect. In order to sustain maximum diversity, it is necessary to develop an approach capable of assessing the genetic differences between individuals. The use of routine sets of cattle microsatellite markers in parentage and identity analysis of bison was ineffective in comparison to bovine SNP markers (Tokarska et al. 2009). Since bovine SNP markers have been effectively used to evaluate genetic variability between European and American bison (Pertoldi et al. 2010a, b) we hypothesized that the same panel of markers could also prove useful in differentiating between two lines of European bison. Therefore the aim of our study was to find SNP markers of significantly different frequency between the Lowland and Lowland-Caucasian lines of European bison.

Ten males, 5 Lowland-Bialowieza (originated from Bialowieza Forest, eastern Poland) and 5 Lowland-Caucasian (one from breeding center in Hanau, Germany, one from zoo in Karlsruhe, Germany, two from German breeding center in Hardehausen and one from Vanatori Neamt, Romania), were included in the analysis. Genomic DNA was isolated from peripheral blood by the standard phenol-chloroforme method (Sambrook and Russel 2001) The selection of samples was based on the animals' pedigree in order to obtain the widest possible access to DNA sequence diversity of the species.

SNPs were genotyped by the BovineSNP50 BeadChip in accordance with the Infinium II assay protocol provided by the vendor (Illumina Inc., USA). The scanned bead intensities were uploaded to the BeadStudio Software for allelic discrimination. SNP genotypes were called by applying our 
Table 1 Frequency of the most polymorphic SNPs identified in two European bison lines by the use of the Bovine 50 K BeadChip

\begin{tabular}{|c|c|c|c|c|c|c|c|c|c|c|}
\hline \multirow[t]{2}{*}{ Illumina SNP id } & \multirow[t]{2}{*}{ BTA } & \multirow[t]{2}{*}{ Position } & \multicolumn{4}{|c|}{ Lowland-Caucasian } & \multicolumn{4}{|c|}{ Lowland-Bialowieza } \\
\hline & & & AA & $\mathrm{AB}$ & BB & $\mathrm{AF}$ & AA & $\mathrm{AB}$ & $\mathrm{BB}$ & $\mathrm{AF}$ \\
\hline ARS-BFGL-NGS-66185 & $\mathrm{Nd}$ & $\mathrm{Nd}$ & 3 & 0 & 2 & 0.6 & 0 & 4 & 1 & 0.4 \\
\hline ARS-BFGL-NGS-41048 & 1 & 9467428 & 1 & 4 & 0 & 0.6 & 1 & 0 & 4 & 0.2 \\
\hline ARS-BFGL-NGS-12781 & 1 & 44192992 & 1 & 0 & 4 & 0.2 & 1 & 3 & 1 & 0.5 \\
\hline BTB-00028383 & 1 & 60178480 & 1 & 0 & 4 & 0.2 & 1 & 3 & 1 & 0.5 \\
\hline Hapmap49986-BTA-41525 & 1 & 92476464 & $\mathbf{0}$ & 3 & 2 & 0.3 & $\mathbf{0}$ & $\mathbf{0}$ & 5 & $\mathbf{0}$ \\
\hline BFGL-NGS-115502 & 1 & 110424873 & 2 & 1 & 2 & 0.5 & 5 & $\mathbf{0}$ & $\mathbf{0}$ & 1 \\
\hline BTB-01739873 & 2 & 4801624 & $\mathbf{0}$ & $\mathbf{0}$ & 5 & $\mathbf{0}$ & $\mathbf{0}$ & 3 & 2 & 0.3 \\
\hline Hapmap57810-rs29009951 & 4 & 60064362 & 1 & 1 & 3 & 0.3 & 3 & 2 & 0 & 0.8 \\
\hline BTB-00190917 & 4 & 61799339 & 0 & 3 & 2 & 0.3 & 3 & 2 & 0 & 0.8 \\
\hline ARS-BFGL-NGS-98675 & 4 & 62998179 & 0 & 3 & 2 & 0.3 & 2 & 3 & 0 & 0.7 \\
\hline ARS-BFGL-NGS-25648 & 4 & 105339490 & 3 & 0 & 2 & 0.6 & 2 & 3 & 0 & 0.7 \\
\hline ARS-BFGL-NGS-40375 & 5 & 39080768 & 1 & 3 & 1 & 0.5 & 4 & 0 & 1 & 0.8 \\
\hline Hapmap44326-BTA-97746 & 5 & 44075127 & 1 & 3 & 1 & 0.5 & 2 & 0 & 3 & 0.4 \\
\hline ARS-BFGL-NGS-106229 & 5 & 76653385 & $\mathbf{0}$ & 4 & 1 & 0.4 & $\mathbf{0}$ & $\mathbf{0}$ & 5 & $\mathbf{0}$ \\
\hline ARS-BFGL-NGS-19374 & 6 & 19635119 & 5 & $\mathbf{0}$ & $\mathbf{0}$ & 1 & 2 & 3 & $\mathbf{0}$ & 0.7 \\
\hline BTB-00247050 & 6 & 23999005 & $\mathbf{0}$ & $\mathbf{0}$ & 5 & $\mathbf{0}$ & $\mathbf{0}$ & 3 & 2 & 0.3 \\
\hline ARS-BFGL-NGS-105928 & 7 & 15388000 & 2 & 1 & 2 & 0.5 & 1 & 4 & 0 & 0.6 \\
\hline ARS-BFGL-NGS-4748 & 8 & 91843006 & 0 & 5 & 0 & 0.5 & 1 & 2 & 2 & 0.4 \\
\hline BTA-63276-no-rs & 10 & 32433588 & 0 & 3 & 2 & 0.3 & 3 & 2 & 0 & 0.8 \\
\hline BTA-109248-no-rs & 10 & 32788633 & 0 & 3 & 2 & 0.3 & 3 & 2 & 0 & 0.8 \\
\hline BTB-01693217 & 10 & 73839537 & 5 & $\mathbf{0}$ & $\mathbf{0}$ & 1 & 2 & 3 & $\mathbf{0}$ & 0.7 \\
\hline BFGL-NGS-111061 & 11 & 65165953 & 3 & 1 & 1 & 0.7 & 0 & 3 & 2 & 0.3 \\
\hline BFGL-NGS-118242 & 12 & 76421077 & 3 & 0 & 2 & 0.6 & 0 & 1 & 4 & 0.1 \\
\hline BTB-01221050 & 13 & 5115476 & 2 & 3 & 0 & 0.7 & 4 & 0 & 1 & 0.8 \\
\hline ARS-BFGL-NGS-31806 & 13 & 7017902 & 0 & 3 & 2 & 0.3 & 1 & 0 & 4 & 0.2 \\
\hline Hapmap51967-BTA-118944 & 13 & 50465144 & $\mathbf{0}$ & $\mathbf{0}$ & 5 & $\mathbf{0}$ & $\mathbf{0}$ & 3 & 2 & 0.3 \\
\hline ARS-BFGL-NGS-73404 & 13 & 54520958 & 0 & 3 & 2 & 0.3 & 1 & 0 & 4 & 0.2 \\
\hline ARS-BFGL-NGS-80508 & 17 & 11758012 & 2 & 1 & 2 & 0.5 & 1 & 4 & 0 & 0.6 \\
\hline BTB-00712788 & 18 & 39089580 & 0 & 4 & 1 & 0.4 & 2 & 1 & 2 & 0.5 \\
\hline UA-IFASA-6363 & 19 & 49300176 & 3 & 2 & 0 & 0.8 & 3 & 0 & 2 & 0.6 \\
\hline BFGL-NGS-116479 & 19 & 60061510 & 3 & 2 & 0 & 0.8 & 1 & 1 & 3 & 0.3 \\
\hline ARS-BFGL-NGS-25782 & 20 & 19944713 & 3 & 0 & 2 & 0.6 & 2 & 3 & 0 & 0.7 \\
\hline BFGL-NGS-113813 & 20 & 22907534 & 2 & 1 & 2 & 0.5 & 0 & 4 & 1 & 0.4 \\
\hline UA-IFASA-2222 & 20 & 63516165 & 3 & 0 & 2 & 0.6 & 1 & 3 & 1 & 0.5 \\
\hline ARS-BFGL-NGS-1258 & 21 & 19249454 & 1 & 3 & 1 & 0.5 & 4 & 0 & 1 & 0.8 \\
\hline ARS-BFGL-NGS-103282 & 21 & 28253892 & 3 & 1 & 1 & 0.7 & 0 & 3 & 2 & 0.3 \\
\hline BFGL-NGS-113562 & 21 & 29903480 & $\mathbf{0}$ & $\mathbf{0}$ & 5 & $\mathbf{0}$ & $\mathbf{0}$ & 3 & 2 & 0.3 \\
\hline Hapmap26098-BTA-122988 & 21 & 32720745 & $\mathbf{0}$ & $\mathbf{0}$ & 5 & $\mathbf{0}$ & $\mathbf{0}$ & 3 & 2 & 0.3 \\
\hline Hapmap35241-BES8_395_800 & 21 & 40229689 & 0 & 3 & 2 & 0.3 & 2 & 3 & 0 & 0.7 \\
\hline Hapmap31415-BTA-135986 & 21 & 46628462 & $\mathbf{0}$ & 5 & $\mathbf{0}$ & 0.5 & $\mathbf{0}$ & $\mathbf{0}$ & 5 & $\mathbf{0}$ \\
\hline BTA-52559-no-rs & 21 & 56077021 & 0 & 2 & 3 & 0.2 & 1 & 4 & 0 & 0.6 \\
\hline ARS-BFGL-BAC-30967 & 22 & 48340850 & 2 & 0 & 3 & 0.4 & 3 & 2 & 0 & 0.8 \\
\hline ARS-BFGL-NGS-104605 & 22 & 49065779 & 2 & 0 & 3 & 0.4 & 3 & 2 & 0 & 0.8 \\
\hline BTA-55821-no-rs & 23 & 28064091 & 2 & 3 & 0 & 0.7 & 4 & 0 & 1 & 0.8 \\
\hline Hapmap36809-140402_6904 & 23 & 48193360 & 5 & $\mathbf{0}$ & $\mathbf{0}$ & 1 & 1 & $\mathbf{0}$ & 4 & 0.2 \\
\hline ARS-BFGL-NGS-85094 & 24 & 1926935 & $\mathbf{0}$ & $\mathbf{0}$ & 5 & $\mathbf{0}$ & 1 & 2 & 2 & 0.4 \\
\hline ARS-BFGL-NGS-28636 & 27 & 40970044 & $\mathbf{0}$ & 4 & 1 & 0.4 & $\mathbf{0}$ & $\mathbf{0}$ & 5 & $\mathbf{0}$ \\
\hline
\end{tabular}


Table 1 continued

\begin{tabular}{|c|c|c|c|c|c|c|c|c|c|c|}
\hline \multirow[t]{2}{*}{ Illumina SNP id } & \multirow[t]{2}{*}{ BTA } & \multirow[t]{2}{*}{ Position } & \multicolumn{4}{|c|}{ Lowland-Caucasian } & \multicolumn{4}{|c|}{ Lowland-Bialowieza } \\
\hline & & & AA & $\mathrm{AB}$ & $\mathrm{BB}$ & $\mathrm{AF}$ & AA & $\mathrm{AB}$ & $\mathrm{BB}$ & $\mathrm{AF}$ \\
\hline ARS-BFGL-NGS-32087 & 28 & 38454795 & 0 & 5 & 0 & 0.5 & 2 & 1 & 2 & 0.5 \\
\hline ARS-BFGL-NGS-90023 & 29 & 11772787 & 2 & 2 & 1 & 0.6 & 1 & 0 & 4 & 0.2 \\
\hline ВТВ-01007059 & 29 & 12323056 & 1 & 2 & 2 & 0.4 & 4 & 0 & 1 & 0.8 \\
\hline
\end{tabular}

$B T A$ bos taurus autosome, $A F$ frequency of A allele, $N d$ no data (SNP not mapped). SNPs monomorphic in one of the bison line and polymorphic in the other are marked in bold

own SNP cluster obtained during research carried out on dairy cattle as part of the genomic selection program (Szyda et al. 2011). The reliability of samples was assessed by the Call Rate option to remove non-reliable samples. All polymorphic SNPs were checked manually to ensure correct calls of clusters and were accepted only when the cluster of bison samples was located within the same range of intensity as in cattle. Finally, the standard Chi-square test was applied to find significant differences in allele frequency between the lines.

The total call rate of the 10 genotyped samples amounted to $93.5 \%$. Among 54,001 SNPs, 1,337 SNPs (2.8\%) turned to be polymorphic. Chi-square analysis revealed significant $(P<0.05)$ differences in allele frequencies of 50 SNPs for the LB and the LC lines (Table 1). Fourteen of them were monomorphic in one of the lines and polymorphic in the other and, therefore, they were the most informative SNPs differentiating between the two lines. Pertoldi et al. (2010a, b) analyzed 50 European bison and found 929 SNPs to be polymorphic. The lower number of polymorphic markers was probably caused by the fact that LC bison were not included in their study and all analyzed European bison come from a single population in the Bialowieza forest, (belonging to LB line). According to pedigree studies the two genetic lines show a different level of genetic variability. The number of founders is different: 7 for LB line and 12 for LC (Olech 2005). In consequence, the level of inbreeding is higher and the genetic variability lower in the LB population. The results confirm very low genetic variability of European bison and provide a new tool for finding genetic differences between two bison lines. Tokarska et al. (2009) suggest that 80-90 randomly selected loci, or just 50-60 of the most heterozygous loci, would be sufficient in ensuring successful paternity and identity analysis in this species. Markers listed in Table 1 are good candidates for such an approach, although more animals of both lines should be included in the research to validate the frequency data prior to practical implementation. Based on the results presented in this paper, a prototype mini-chip (consisting of approximately 50-60 SNPs) can be designed and SNPs can be typed using VeraCode technology (llumina) or the APEX technique, which has previously been successfully applied by us to dairy cattle (Kaminski et al. 2005). Such a chip might be useful in conservation management for estimating the effective population size and for reducing the level of inbred matings in certain sub-populations. It also can have very practical application like translocation and restocking programs (Pertoldi et al. 2010a, b). This should minimize mating between close relatives, and which are currently based on pedigree data (Olech and Perzanowski 2002).

Additionally, it would also be interesting to find out why the regions represented by the 14 SNPs are so hypervariable and whether they contain genes of special role in survival of highly inbred and endangered species, like European bison.

Acknowledgments This work was financially supported by the University of Warmia and Mazury (project no 0105-0804).

Open Access This article is distributed under the terms of the Creative Commons Attribution Noncommercial License which permits any noncommercial use, distribution, and reproduction in any medium, provided the original author(s) and source are credited.

\section{References}

Heptner VG, Nasimovic AA, Bannikov AG (1966) Die Saeugetiere der Sovietunion. 1 Paarhufer und Unpaarhufer. G. Fischer, Jena

Kaminski S, Ahman A, Rusc A, Wojcik E, Malewski T (2005) MilkProtChip - a microarray of SNPs in candidate genes associated with milk protein biosynthesis-development and validation. J Appl Genet 46(1):45-58

Olech W (2005) The genetic structure of European bison (Bison bonasus) lines. Stud Res Vanatori Neamt Natural Park 1: $111-117$

Olech W, Perzanowski K (2002) A genetic background for reintroduction program of the European bison in the Carpathians. Biol Conserv 108:221-228

Pertoldi C, Wojcik JM, Tokarska M, Kawałko A, Kristensen TN, Loeschcke V, Gregersen VR, Coltman D, Wilson GA, Randi E, Henryon M, Ch Bendixen (2010a) Genome variability in European and American bison detected using the BovineSNP50 BeadChip. Conserv Genet 11:627-634

Pertoldi C, Tokarska M, Wójcik JM, Kawałko B, Randi E, Kristensen TN, Loeschcke V, Coltman D, Wilson GA, Gregersen VR, Ch Bendixen (2010b) Phylogenetic relationships among the European and American bison and seven cattle breeds reconstructed 
using the BovineSNP50 Illumina Genotyping BeadChip. Acta Theriol 55(2):97-108

Pucek Z, Belousova IP, Krasinski ZA, Krasinska M, Olech W (2004) European bison status survey and conservation action plan IUCN/SSC bison specialist group. IUCN, Gland

Sambrook J, Russel DW (2001) Molecular cloning a laboratory manual, 3rd edn. Cold Spring Harbour Laboratory Press, New York
Szyda J, Zarnecki A, Suchocki T, Kamiński S (2011) Fitting and validating the genomic evaluation model to Polish HolsteinFriesian cattle. J Appl Genet 52(3):363-366

Tokarska M, Marshall T, Kowalczyk R, Wojcik JM, Pertoldi C, Kristensen TN, Loeschcke V, Gregersen VR, Bendixen C (2009) Effectiveness of microsatellite and SNP markers for parentage and identity analysis in species with low genetic diversity: the case of European bison. Heredity 103:326-332 